\title{
Burkina Faso: Poverty Reduction Strategy Paper Annual Progress Report- Joint Staff Advisory Note
}

The attached Joint Staff Advisory Note (JSAN) of the Poverty Reduction Strategy Paper Progress Report for Burkina Faso, prepared by the staffs of both the World Bank and IMF, was submitted with the member country's Poverty Reduction Strategy Paper (PRSP) or Interim PRSP (IPRSP) to the Executive Boards of the two institutions. A JSAN evaluates the strengths and weaknesses of a country's poverty reduction objectives and strategies, and considers whether the PRSP or IPRSP provides a sound basis for concessional assistance from the Bank and Fund, as well as for debt relief under the Enhanced Heavily Indebted Poor Countries (HIPC) Debt Initiative. The Boards then decide whether the poverty reduction strategy merits such support.

To assist the IMF in evaluating the publication policy, reader comments are invited and may be sent by e-mail to publicationpolicy@imf.org.

Copies of this report are available to the public from

International Monetary Fund • Publication Services

$70019^{\text {th }}$ Street, N.W. • Washington, D.C. 20431

Telephone: (202) 623-7430 • Telefax: (202) 623-7201

E-mail: publications@imf.org • Internet: http://www.imf.org

\section{International Monetary Fund Washington, D.C.}





\author{
INTERNATIONAL MONETARY FUND AND \\ INTERNATIONAL DEVELOPMENT ASSOCIATION
}

\author{
BURKINA FASO \\ Joint Staff Advisory Note on the Poverty Reduction Strategy Paper \\ Annual Progress Report \\ Prepared by the Staffs of the International Monetary Fund (IMF) and \\ International Development Association (IDA) \\ Approved by Thomas Krueger and Mark Plant (IMF) \\ and Hart Schafer, Acting Vice President (IDA)
}

May 24, 2007

\title{
I. OVERVIEW
}

1. This Joint Staff Advisory Note (JSAN) reviews the sixth annual progress report (APR) on the implementation of Burkina Faso's Poverty Reduction Strategy (PRS). ${ }^{1}$ This APR covers PRS implementation in 2005. The APR was submitted in May 2006.

2. The PRS is based on four guiding pillars: (i) accelerating broad-based growth; (ii) improving access to basic social services for the poor; (iii) increasing employment and income-generating activities for the poor; and (iv) promoting good governance. The prime objectives of the poverty reduction strategy were:

- $\quad$ increasing per capita gross domestic product by at least 4 percent per year, which requires an annual growth rate of above 6 percent;

- $\quad$ reducing the incidence of poverty from 46.4 percent in 2003 to under 35 percent by 2015; in line with the Millennium Development Goals (MDGs); and

- $\quad$ increasing life expectancy to at least 60 years by 2015 .

\footnotetext{
${ }^{1}$ The latest PRS dates from July 2004 and covers the period 2004 to 2006. The previous JSAN on the 2004 APR was issued on August 15, 2006. The 2006 APR is expected to be completed in April 2007, and the next full PRSP is planned for 2009. The PRSP is updated and rolled-over annually in form of the government's Priority Action Program (PAP).
} 
3. The APR notes that poverty has been further reduced to an estimated 42 percent in 2005 from an estimated 54 percent in $1998 .^{2}$ Poverty declined owing mostly to a reduction in the incidence of rural poverty. The APR also informs about progress made regarding access to basic services, employment opportunities for the poor and improved governance. While favorable weather conditions applied, progress in poverty reduction took place against a background of a difficult external economic environment, described by rising import prices for petroleum products and an appreciating currency, which resulted in declining cotton export prices.

\section{A. Accelerating Broad-Based Growth}

4. The APR adequately describes macroeconomic developments in 2005. The government is to be commended for maintaining macroeconomic stability despite a difficult external environment. Given the importance of mobilizing resources to meet ambitious poverty reduction objectives and the MDGs, the staffs recommend, as for the past JSAN, to use the APR for a more in-depth discussion of measures that could increase domestic revenues. These would include strengthening tax and customs administration, and broadening the tax base, while taking into account Burkina Faso's economic potential and its commitments towards the West African Economic and Monetary Union. The absorptive capacity could be improved through better public financial management, especially by developing sectoral medium-term expenditure frameworks, and a successful conclusion of the on-going public procurement reform. Moreover, the next APR should discuss the use of debt relief under the Multilateral Debt Reduction Initiative (MDRI).

5. The staffs agree with the thrust of the APR discussions in the area of growth and macroeconomic stability. The macroeconomic framework for 2006-08 described in the APR remains broadly appropriate and is comparable with the macroeconomic framework used for the Poverty Reduction and Growth Facility (PRGF) arrangement discussed by the IMF Board in April 2007. Real GDP growth in the APR projected to be 7 percent on averagemarginally higher than in the new PRGF arrangement, while inflation and reserves are basically unchanged. The budget deficit including grants is similar.

6. The staffs support the government in its desire to maximize income and employment opportunities by (i) enhancing the business climate, (ii) improving competitiveness, including through reduction of factor costs, (iii) promoting regional integration, and (iv) developing the service sector. The staffs urge the government to accelerate implementation of measures in these areas, especially regarding the increased private sector participation and better incentives, notably in the electricity and oil import sectors. This will enhance investment and free up public resources for core poverty reduction areas.

7. Broadening and diversifying exports remains indispensable for sustained growth and long-term poverty reduction. In that regard the staffs recommend that the APR be used for a

\footnotetext{
2 The estimate is made by Burkinabé authorities based on projections using available macroeconomic, social and poverty information and published in the sixth APR, page 20.
} 
broader discussion of policy choices. The staffs suggest that the Diagnostic Trade Integration Study (DTIS), when available, be used to identify policy choices and formulate appropriate policy measures.

8. The staffs recognize the key role of agriculture as a source of growth and poverty reduction in Burkina Faso. While economic growth in agriculture has been strong in 2005, it was mainly due to favorable rainfall conditions for cereal and cotton production, the latter partly on account of unsustainably high cotton producer prices. The sector remains very vulnerable to weather conditions and world market prices, and thus risks remain considerable for sustaining the high growth rate achieved since 2005. The staffs recommend that the government uses the forthcoming APR to discuss possible measures to raise productivity and strengthen the robustness of the sector in general, and to ensure the medium-term viability of the cotton sector in particular.

\section{B. Promoting Access to Basic Social Services by the Poor}

9. While Burkina Faso is making progress towards reducing overall poverty, the staffs note that, assuming continuation of the current trend, some MDGs may not be met by 2015 . Furthermore, the staffs suggest, as a follow-up to previous JSANs, that future APRs report on progress made towards the MDGs. In this regard, an important step forward would be completion of the ongoing costing of key sector policies.

10. The APR underlines the progress made in the education sector during the period covered. In basic education, the gross enrollment rate (GER) in primary education improved from 40 percent in 2004 to 47 percent in 2005 . In the 20 priority provinces, the gross intake rate (GIR) improved from 47 percent in 2004 to 60 percent in 2005, a significant progress for these disadvantaged rural provinces. However, further improvements, both in terms of access and quality, need to be achieved. The APR lacks a discussion on possible measures which could lead to such further improvements. Given the high need for education services and capacity, a policy of monitoring costs in the sector would be highly desirable.

11. The expansion in primary education identified in the APR calls for a rapid and coordinated expansion of secondary education and vocational education. The government is in a process of adding lower secondary education to basic education, and is designing a policy on vocational training. However, a scaling up of these efforts is necessary.

12. The government is to be commended for beginning to implement in five provinces policies facilitating decentralization in the education sector, particularly concerning the transfer of resources and authority to the communities to directly provide support to schools and learning materials to students. An evaluation of this first experience in the next APR will be important in order to derive the right lessons for a scaled-up approach on using more effectively scarce resources.

13. The APR restates the government's goal to reach the MDGs in the water and sanitation sector. If current investment trends are sustained, an additional 5 million people would have access to potable water supply by 2015, and an additional 7 million to sanitation. 
Burkina Faso would thus be in the position to meet this MDG. However, with the spatial and quantitative extension of the water supply and sanitation system, greater attention must be paid to maintenance and the sustainability of services, particularly in rural areas. Full implementation of the envisaged water system management reform becomes therefore imperative, especially concerning the facilitation of local public private partnerships. Finally, more efforts need to be undertaken on the sanitation side, if the full benefit of investment in water supply is to materialize. The government should therefore take decisive steps, including through the national sanitation strategy, to promote better hygiene and sanitation standards nation wide.

14. The APR expresses satisfaction with results obtained in the health sector during 2005 . Although progress has been made, the sector is unlikely to meet the MDGs. In addition, important concerns remain regarding the efficient use of resources and the equity of resource allocation. The report does not discuss the link between policies, outcomes, and the resources available for this priority sector. Resources have stagnated as a ratio of GDP during 2003 to 2005. More efforts have to be undertaken to increase health sector financing, with priority given to interventions necessary to achieve the MDGs. Regarding equity concerns, the staffs recommend to consider the subsidized distribution of new malaria drugs and to provide adequate financing for increased coverage of essential child and reproductive health services at district and community levels, especially for the poorest.

15. While resources for the public health sector remain insufficient, existing resources could be more efficiently allocated. The Medium Term Expenditure Framework (MTEF) of the Ministry of Health, which was first developed in 2004/05, should be used and further developed to meet the requirements of a results-based framework. This would strengthen the Ministry of Health's ability to argue more convincingly for additional resources to achieve its strategic goals.

16. The staffs are encouraged by the relatively low human immunodeficiency virus (HIV) prevalence rate, which appears to have stabilized at about 2.3 percent. The government's fight against HIV/AIDS is based on a medium-term strategy, stretching to the year 2010 . However, the APR could have analyzed in more depth the diverging trends embodied in the overall national trend, thereby identifying early potential risks to the success of the overall AIDS strategy. For example, the overall population living with AIDS continues to rise (due to the time lag of the outbreak of the disease), particularly in urban areas, posing a potential future risk. The staffs recommend including in future APRs a more explicit discussion of HIV/AIDS trends in Burkina Faso.

17. The APR discusses a number of social protection programs that benefit different vulnerable groups, most notably orphans and vulnerable children, youth and women. Because of the lack of program data, however, it is difficult to analyze the true impact of these programs on the well-being of the poor. There is an urgent need to evaluate, streamline and consolidate the existing interventions managed by various Ministries, and to begin collecting critical data about the effectiveness of this array of programs, and explore how the more efficient ones can be sustained with multi-year commitments of resources. The work carried 
out for the preparation of national social protection strategy gives a unique opportunity for such a review. In this context, the staffs urge the authorities to finalize the social protection strategy, which would provide needed guidance.

\section{Increasing Employment and Income-Generating Activities for the Poor}

18. The APR underlines that the agriculture sector has been a driver of growth in 2005, contributing about 4 percent to the overall growth rate of 7 percent. The increased production of both cotton and cereals led to this result. Sustaining the result through improving productivity in the agriculture sector and enhancing its competitiveness will remain a prime challenge for the government. While the government's agriculture sector policies, including the focus on strengthening of land rights, are generally supported by the staffs, the APR lacks a strategic and coherent approach on how to obtain the required productivity gains to sustain growth in agriculture. In particular, the APR lacks an assessment of the risks and opportunities of cotton production in Burkina Faso, the country's most important cash crop.

19. The APR points correctly to the success achieved in building an infrastructure, which links remote areas with the main markets, a key to provide income opportunities for many poor. The staffs recommend that increased attention be paid to improving the management of road maintenance. With the extension of the road system, the efficient use of the funds for road maintenance is a key element for the sector's performance. The staffs are of the view that the government should weigh its policy choices in this regard, to ensure adequate availability of resources, and to pay suppliers within a reasonable period after service delivery.

20. The APR discusses labor market issues and employment creation under the angle of institution building and training opportunities. While improvement in this area is indispensable, the staffs recommend that future APRs also serve as a basis to assess critically the regulatory framework of the labor market in Burkina Faso. The conditions of the market are perceived not to be competitive by stakeholders, a point underlined also by the World Bank's Doing Business Indicators for Burkina Faso. The report refers to studies undertaken on youth employment and on the evolution of the employment situation in Burkina Faso, but the main policy conclusions of such studies are not referred to in the APR.

\section{Promoting Good Governance}

21. The staffs encourage the government to fully implement its strategy for good governance, which has been adopted in August 2005. The staffs recommend that the key policy lines of the strategy and their respective implementation be identified and discussed in the next APR. Furthermore, the staffs propose to maintain a wide and inclusive dialogue with civil society on cross-cutting policy issues and to strengthen the government's dialogue with civil society on governance issues.

22. The staffs recommend to critically review the government's procurement regulation and administration, in line with recommendation made in the Country Procurement Assessment Report (CPAR) of 2005, especially with regard to the functioning of the Central 
Directorate for Public Procurement (DCMP), which should separate implementation and regulating functions.

23. The staffs consider that a strengthening of the external financial oversight bodies, such as the Audit Court, the administrative inspection bodies, and the High Authority for the Coordination of the Fight against Corruption (HACLC) is indispensable. A strengthening would include technical capacity, the reporting mandate, and an increase in budget resources. Additional resources should be included in the MTEF and in the annual budgets to enhance the effectiveness of these oversight institutions.

24. Regarding implementation of the public sector reform, the staffs support the government in its critical assessment of what remains to be done to make this reform work. While the various weaknesses in the application of the reform are noted in the APR, the report does not, however, comment on the ongoing efforts to implement a performance evaluation policy in the civil service to better align performance and incentives for the civil servants. The staffs recommend to refer to the status of these efforts in the ensuing APR.

25. With regard to local governance, the report rightly points out that to avoid service disruptions, the transfer of resources and competences to local government needs to go in parallel with the necessary capacity building and an appropriate financial framework. However, the APR could usefully provide guidance on the coordination and technical assistance arrangements between the decentralized administrative level and local governments, to clarify the types of inputs the decentralized administration will provide to the local governments, and the types of reporting and monitoring arrangements which will be put in place.

\section{E. Monitoring and Evaluation}

26. A deepening of the monitoring system would strengthen PRS implementation. While the monitoring system of the PRS has significantly advanced since inception in 2000, many monitoring indicators applied especially to the sectors suffer from weak and delayed statistical information, making effective monitoring difficult in many cases. The staffs encourage the government to strengthen the monitoring system in sector policies, as suggested in the APR. The establishment of sector-oriented MTEF, as envisaged by the government, are a first step in the right direction.

\section{Conclusion}

27. The staffs commend the authorities for their effort to maintain an environment of macroeconomic stability, in light of significant external shocks. While the government has made progress in poverty reduction through maintaining a good track record of policy implementation, based on current projections, some of the MDGs may not be met. Medium term risks for the PRS strategy originate from the vagaries of the weather conditions in Burkina Faso and potential delays in improving productivity in agriculture and achieving export diversification. To sustain high growth and continue to make progress on poverty reduction, it is indispensable to raise domestic revenues, improve the business climate, 
restore the viability of the cotton sector, and diversify exports. The staffs have underlined several areas where PRS implementation could be strengthened and they urge the authorities to consider and implement these recommendations. In particular, the staffs would like to stress the importance of:

- Modernizing revenue administrations and reforming the tax regime;

- Restoring the economic viability of the cotton sector;

- Broadening the economic base and diversifying exports;

- Enhancing the efficiency of service delivery in education and health; and

- Accelerating good governance and anti-corruption efforts. 